\title{
AGLOMERAÇÃO DE PROTEÍNA CONCENTRADA DE ARROZ UTILIZANDO SOLUÇÃO DE SERICINA COMO LIGANTE: MONITORAMENTO IN-LINE DO TAMANHO DE PARTÍCULA
}

\author{
F. N. RUSSO ${ }^{1}$, K. ANDREOLA ${ }^{1}$ e O. P. TARANTO ${ }^{1}$ \\ ${ }^{1}$ Universidade Estadual de Campinas, Faculdade de Engenharia Química \\ E-mail para contato: felipe09nrusso@gmail.com
}

\begin{abstract}
RESUMO - Este trabalho apresenta estudos sobre a aglomeração de proteína concentrada de arroz utilizando soluções de sericina como ligante. Foi realizado monitoramento in-line do tamanho das partículas durante os ensaios a fim de obter a dinâmica de crescimento do material. Assim, os testes representaram melhoras nas propriedades de fluidez e molhabilidade do pó de proteína. Além disso, foram analisadas a influência da concentração e da quantidade de ligante atomizado no tamanho final das partículas e nas características do produto final.
\end{abstract}

\section{INTRODUÇÃO}

As mudanças no estilo de vida e hábitos alimentares da população nos últimos anos tem estimulado o aumento no consumo de alimentos industrializados de fácil preparo e consumo. No entanto, esses produtos apresentam, na grande maioria, deficiência de nutrientes e excesso de aditivos artificiais o que leva a um padrão de alimentação inadequado (BRASIL, 2006, WHO, 2012). Embora a presença de alimentos industrializados na dieta da sociedade moderna seja evidente, a demanda por produtos saudáveis e nutricionalmente enriquecidos é crescente.

As proteínas do grão de arroz destacam-se devido as suas propriedades nutritivas, nutracêuticas e funcionais (SAUNDERS, 1990), são ricas em aminoácidos essenciais e apresentaram maior digestibilidade em comparação com a maioria das proteínas dos demais cereais (JULIANO, 1993). Por serem de origem vegetal, isentas de glúten e lactose, as proteínas do arroz são hipoalergênicas, podendo fazer parte de dietas infantis e especiais (HELM e BURKS, 1996). No entanto, a maioria dos pós proteicos de arroz disponíveis comercialmente são produtos com partículas muito finas e coesivas, o que dificulta sua dispersão em líquidos (instantaneização) e compromete a sua utilização em processos industriais, podendo causar o entupimento de tubulações devido à dificuldade de escoamento e também impedir uma mistura homogênea quando utilizado em formulações.

$\mathrm{Na}$ indústria de alimentos, o processo de aglomeração, que consiste na transformação de partículas finas em agregados de partículas, é utilizado na produção de alimentos instantâneos, que possuem capacidade de se reconstituir rapidamente quando misturados em água ou leite (SCHUBERT, 1993). Sendo assim, o processo de aglomeração representa uma alternativa interessante para melhorar as propriedades de instantaneização da proteína concentrada de arroz em pó, viabilizando a sua utilização em diversas aplicações industriais. 
Leitos fluidizados são amplamente utilizados para a aglomeração de partículas, pois apresentam elevadas taxas de transferência de calor e de massa (KUNII e LEVENSPIEL, 1991). A aglomeração em leitos fluidizados é realizada pela atomização de um líquido ligante (material que tem como função favorecer e/ou melhorar a adesão de partículas individuais) sobre partículas em movimento agitado, de modo que o gás utilizado para fluidização das partículas também proporciona a evaporação do ligante e a secagem do material (PONT et al., 2001).

\section{MATERIAIS E MÉTODOS}

\subsection{Matéria-prima e Ligante}

A matéria-prima utilizada nos ensaios foi proteína isolada de arroz em pó. Foram testadas como ligantes sericina pura e uma solução aquosa de 50\% em massa de sericina.

\subsection{Descrição do Sistema Experimental e Experimentos}

Os experimentos foram realizados num leito fluidizado de base cônica de 0,6 $\mathrm{m}$ de altura e $0,15 \mathrm{~m}$ de diâmetro. Para a distribuição homogênea do ar, foi utilizado uma placa perfurada com buracos de 0,001 m. Um soprador (WEG, 7,5 HP), ligado a um inversor de frequência (WEG, CFW 08), forneceu o ar de fluidização. A temperatura do ar no processo era controlada por meio de uma resistência elétrica e monitorada por termoresistências do tipo Pt-100. A fim de medir a temperatura e a umidade, dois termo-higrômetros (NOVUS, RHTXS) foram instalados na entrada e saída do sistema. O ligante, juntamente com o ar comprimido, passava por um spray responsável pela atomização do líquido, a qual foi realizada contracorrente ao fluxo do ar de fluidização. O ligante foi bombeado por uma bomba peristáltica (Cole Parmer, Masterflex L/S). Os dados foram aquisitados pelo sistema NI cDAQ-9172 (National Instruments) e processados no software LabVIEW 8.6TM.

Os testes foram realizados com $0,4 \mathrm{~kg}$ de matéria-prima, com o ar de fluidização a temperatura de $75^{\circ} \mathrm{C}$, com velocidade de $0,6 \mathrm{~m} / \mathrm{s}$ e o ar de atomização a $69 \mathrm{kPa}$. A vazão de ligante durante os testes foi de $2 \mathrm{~mL} / \mathrm{min}$. Passado o tempo de atomização, o material passa pela secagem, em que a vazão de ligante é cessada e o experimento termina quando a umidade do material fica próxima a 3,5\%. No Teste 1, após 40 minutos de aglomeração a atomização de ligante foi desligada para início da secagem. Já nos testes 2 e 3, a aglomeração teve tempo de 50 minutos, totalizando $100 \mathrm{~mL}$ de ligante atomizados. Basicamente, as diferenças entre cada teste consistem na quantidade de ligante atomizado $(80 \mathrm{~mL}$ ou $100 \mathrm{~mL})$ e na concentração do ligante (puro ou $50 \% \mathrm{~m} / \mathrm{m}$ ).

\subsection{Caracterização da Matéria-prima e do Produto Aglomerado}

Tamanho de partícula: durante os ensaios de aglomeração foi realizado o monitoramento in-line (em tempo real e dentro do processo) do tamanho das partículas através da sonda Parsum IPP70S (Mavern Instruments, UK), a qual utiliza o princípio de velocimetria de filtro espacial para medir a velocidade e a "corda" (tamanho) das partículas. $\mathrm{O}$ princípio se baseia na evolução da sombra deixada pelas partículas, a qual é criada quando um feixe de laser atravessa o material particulado que está em movimento. O monitoramento inline do processo é fundamental para entender a dinâmica de crescimento das partículas. 
Fluidez: a análise de fluidez indica a facilidade com que as partículas escoam. A fim de determinar a fluidez, é preciso calcular o Índice de Carr (Equação 1), o qual pode ser interpretado pelo uso da Tabela 1:

Tabela 1: Relação entre o Índice de Carr e a Fluidez do material

\begin{tabular}{cc}
\hline IC & Nível de Fluidez \\
\hline$<15$ & Escoa Livremente \\
$15-20$ & Bom Escoamento \\
$20-35$ & Moderado \\
$35-45$ & Coesivo \\
$>45$ & Muito Coesivo \\
\hline Fonte: TURCHIULI et al., (2005)
\end{tabular}

$\mathrm{IC}=\frac{\rho_{\mathrm{t}}-\rho_{\mathrm{b}}}{\rho_{\mathrm{t}}}$

$\mathrm{Na}$ Equação 1, $\rho_{\mathrm{b}}$ é a densidade do leito de partículas e $\rho_{\mathrm{t}}$ é a densidade do leito de partículas compactado. A primeira é obtida com o auxílio de uma proveta de $25 \mathrm{~mL}$ e balança analítica. São colocados na proveta cerca de $20 \mathrm{~mL}$ de material e através da razão entre a massa e o volume obtidos, $\rho_{\mathrm{b}}$ é calculado. Já para obter $\rho_{\mathrm{t}}$, a mesma proveta é colocada sob agitação no equipamento Autotap Tap Density Analyzer (Quantachrome instruments ${ }^{\circledR}$, model DAT-4) até volume constante. Deste modo, com o novo volume, é possível obter a densidade de leito compactado.

Instantaneização: a análise do tempo de instantaneização consiste em determinar o tempo com que $3 \mathrm{~g}$ de material estejam completamente submersos em água destilada. Para tal, o material é disposto uniformemente sobre uma lâmina conectada a um pino, o qual quando acionado faz a lâmina deslizar rapidamente, promovendo o contato da proteína de arroz com a água. O teste é filmado para que o tempo de instantaneização possa ser determinado com o auxílio de um software editor de vídeos (Windows Movie Maker, por exemplo).

\section{RESULTADOS E DISCUSSÃO}

\subsection{Tamanho de Partícula}

O tamanho médio de partículas (D50) da matéria-prima obtido off-line por difração a laser é de 54,2 $\mu \mathrm{m}$ (ANDREOLA et al., 2017). Após os ensaios de aglomeração, o D50 aumentou para 194,7 $\mu \mathrm{m} ; 177,8 \mu \mathrm{m}$ e 208,0 $\mu \mathrm{m}$ para o Teste 1, Teste 2 e Teste 3, respectivamente. Na Figura 1, podemos observar a dinâmica de crescimento das partículas durante o processo para os três testes. Vale ressaltar que o limite mínimo de medição da sonda é por volta de $50 \mu \mathrm{m}$, gerando assim desvios maiores para o início das medições. 
Figura 1 - Perfil de crescimento do diâmetro médio das partículas, com a: início da secagem; b: final do processo

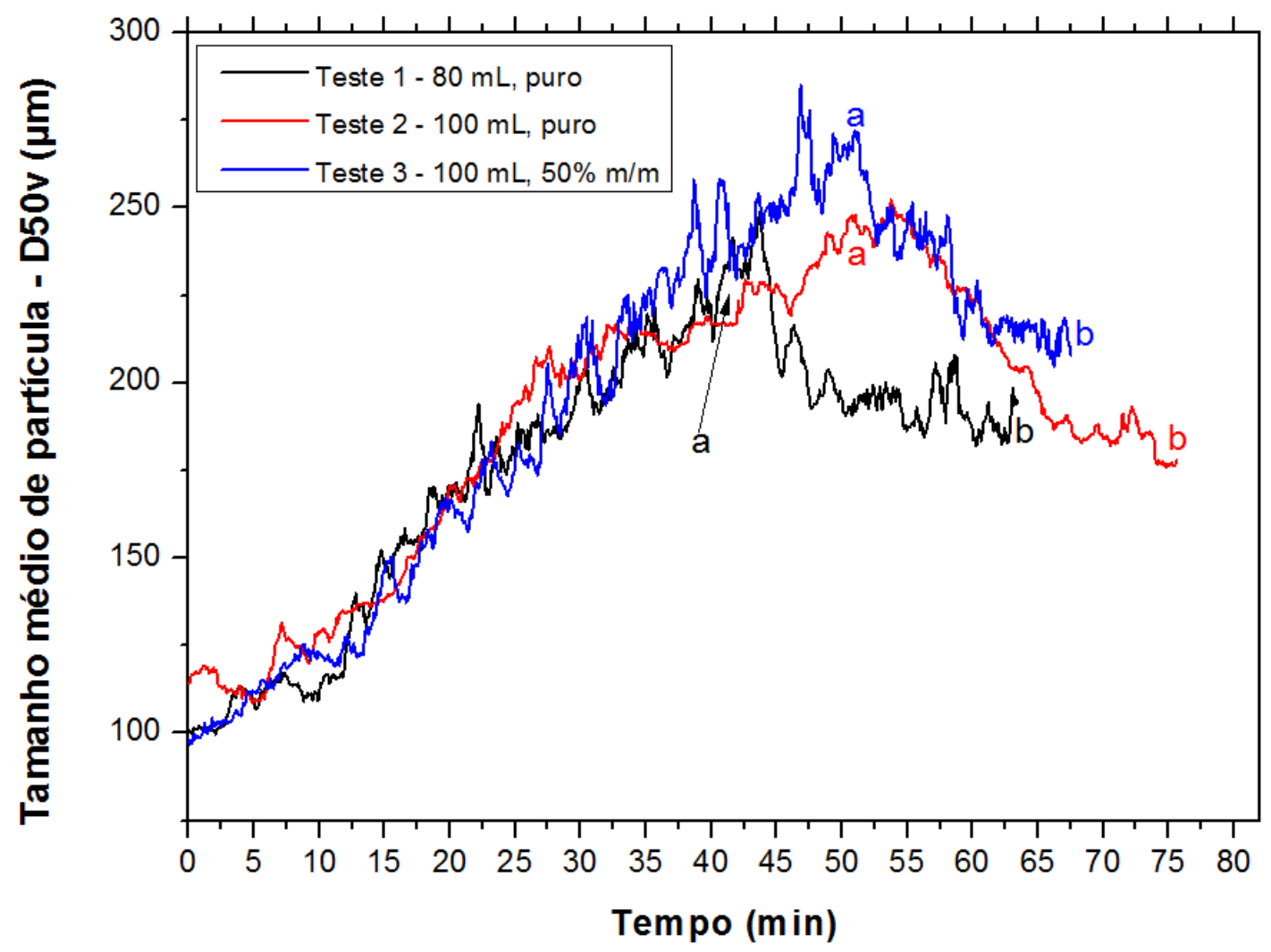

Primeiramente, é possível observar na Figura 1 que o ligante cumpre seu objetivo, uma vez que todos os ensaios resultaram num tamanho de partícula maior que o da matéria-prima.

Quando os testes 1 e 2 são comparados, é possível observar que, como esperado, os dois apresentam praticamente a mesma dinâmica de crescimento. No entanto, o principal motivo dessa comparação é determinar qual a influência no resultado final de mais tempo de atomização, e consequentemente de maior volume de ligante usado no processo. Ao final da secagem, os dois testes resultaram em diâmetros médio de partícula muito próximos. Neste caso, o D50 do Teste 2 foi menor que o do Teste 1, mostrando que a utilização de mais ligante além dos $80 \mathrm{~mL}$ não é necessária, uma vez que não faz diferença no tamanho médio final.

Já a influência da concentração do ligante pode ser observada pela comparação dos testes 2 e 3 . Até os primeiros 35 minutos de atomização, os dois testes apresentam uma dinâmica de crescimento parecida. Depois desse período, a taxa de crescimento do Teste 3 se mostra maior e seu D50 permanece maior que o do Teste 2 até o início da secagem. Uma possível explicação para essa diferença no crescimento pode estar associada à diferença de viscosidade entre o ligante puro e o ligante diluído, uma vez que foi visualmente notável que a solução pura era mais viscosa. De acordo com resultados de Schæfer e Mathiesen (1996), o aumento da viscosidade geralmente limita a dispersão do ligante, fazendo com que sua distribuição leve mais tempo, retardando o crescimento uniforme das partículas. Também é possível observar que o Teste 3 apresenta um tempo de secagem mais rápido, resultando num tamanho médio final superior ao Teste 2. 


\section{2 - Fluidez}

A Figura 2 mostra a melhora na fluidez do material por meio da análise do Índice de Carr. Enquanto o nível de escoamento da matéria-prima era moderado ( $\mathrm{IC}=25,3$ ), todos os produtos aglomerados obtidos apresentaram características de bom escoamento.

Figura 2 - Índice de Carr (IC) da matéria-prima (MT) e dos três produtos aglomerados

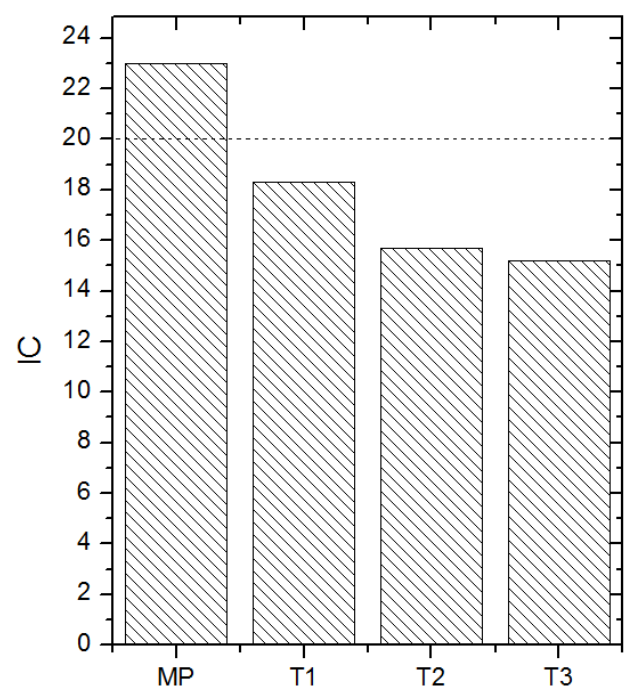

\section{3 - Instantaneização}

As partículas finas e coesivas da matéria-prima apresentam um tempo de instantaneização próximo a dois minutos e meio, enquanto os Testes 1,2 e 3 apresentados no item anterior apresentam 5,8; 5,6 e 6,2 segundos, respectivamente. Deste modo, é possível observar a grande melhora nas propriedades de molhabilidade do material após a aglomeração.

\section{4 - Sólidos Totais}

A análise de sólidos totais presentes no ligante tem como objetivo verificar se a quantidade de sólidos na solução pode chegar a provocar interferências na fluidodinâmica do processo. Os resultados obtidos foram 3,2 $\pm 0,2 \mathrm{mg}$ de sólidos por grama de solução para os testes 1 e 2 e $1,8 \pm 0,1 \mathrm{mg} / \mathrm{g}$ para a solução do Teste 3 , indicando, assim, que a presença de sólidos é desprezível por ser tão baixa. 


\section{CONCLUSÃO}

Verificou-se que a sericina se mostra como um bom ligante para o processo de aglomeração de proteína concentrada de arroz, uma vez que após os ensaios foram constatadas melhorias no tamanho de partícula, fluidez e instantaneização. Além disso, foi constatado que não há melhorias significantes na qualidade do produto quando se aumenta a quantidade de ligante atomizado de $80 \mathrm{~mL}$ para $100 \mathrm{~mL}$. Por fim, o uso de uma solução diluída de sericina se mostrou interessante, já que, além da economia de solução ligante, mostrou secagem mais rápida e tamanho de partícula maior que os outros testes.

\section{REFERÊNCIAS}

ANDREOLA, K; SILVA, C. A. M. da; TARANTO, O. P. Agglomeration process of rice protein concentrate using glucomannan as binder: in-line monitoring of particle size. 2017.

BRASIL. Ministério da Saúde. Guia alimentar para a população brasileira: Promovendo alimentação saudável. Brasília: Editora MS, 2006. Disponível em < http://portal.saude.gov.br/portal/saude/area.cfm?id_area=1444> Acesso em: $15 \mathrm{de}$ março de 2016.

HELM, R.M.; BURKS, A.W. Hypoallerginicity of rice protein. Cereal Foods World,v. 41, p. 839842, 1996.

JULIANO, B. O. Rice in human nutrition. Rome: FAO, 1993. p. 168.

KUNII, D.; LEVENSPIEL, O. Fluidization Engineering. 2.ed. New York: John Wiley, 1991, p. 489

PONT, V.; SALEH, K.; STEINMETZ, D.; HÉMATI, M. Influence of the physicochemical properties on the growth of solid particles by granulation in fluidized bed. Powder Technology, v. 120, p. 97104, 2001.

SAUNDERS, R. M. The properties of rice bran as a foodstuff. Cereal Foods World, v. 35, n. 7, p. 632, 634-636, 1990.

SCHÆFER, T.; MATHIESEN, C. Melt pelletization in a high shear mixer. VIII. Effects of binder viscosity. International Journal of Pharmaceutics, 139 (1996) 125-138.

SCHUBERT H., Instantization of powdered foods, International Chemical Engineering, v. 33, n. 1, p. 28-45, 1993.

TURCHIUli, C.; ElOUALIA, Z.; MANSOURI, N. E.; DUMOULIN, E. Fluidised bed agglomeration: Agglomerates shape and end-use properties. Powder Technology, v. 157, p. 168175, 2005.

WHO, 2012. Disponível em: <http://www.who.int/topics/nutrition/en/index.html>. Acesso em: 27 de maio de 2012. 